\title{
Musikinésia: Jogo Eletrônico para o Aprendizado de Teclado Musical
}

\author{
Rogério A. Bordini, Joice L. Otsuka, Delano M. Beder, Lucas F. Fonseca, Antônio \\ P. A. Nunes, Daniel L. Santiago, Pablo A. G. de Freitas, Glauber L. A. Santiago, \\ Marcia R. G. de Oliveira
}

\author{
Laboratório de Objetos de Aprendizagem (LOA) \\ Universidade Federal de São Carlos (UFSCar), Caixa Postal 676 - CEP: 13565.905 \\ São Carlos/SP - Brasil \\ rogerio.bordini@sead.ufscar.br, \{joice, delano\}@dc.ufscar.br, \\ $\{\mathrm{glauber}, \mathrm{maroz}\}$ @ufscar.br
}

\begin{abstract}
This paper presents the educational game Musikinésia which was designed to help students of music courses in the identification of a musical keyboard, in addition to teaching other basic musical concepts such as tempo, accidentals and music reading. Beyond discussing how game-based learning can effectively contribute with teaching-learning process of musical content and specific care required for good educational games development, the main stages of the Musikinésia's development process are presented, emphasizing both the results obtained by testing it with the target audience and how it helped teacher in their teaching process.
\end{abstract}

Resumo. O presente artigo apresenta o game educacional Musikinésia, projeto idealizado para ajudar alunos de cursos de música na identificação das teclas de um teclado musical, além de ensinar outros conceitos musicais básicos, como andamentos, acidentes e leitura musical. Além de discutir como a aprendizagem baseada em jogos pode contribuir efetivamente com o processo de ensino-aprendizagem de conteúdos específicos musicais e dos cuidados necessários para o desenvolvimento de bons jogos educacionais, são apresentadas as principais etapas do processo de desenvolvimento do jogo, enfatizando os resultados obtidos por meio de testes realizados com o públicoalvo e como os professores utilizaram o game em aplicações em sala de aula.

\section{Introdução}

As discussões sobre a utilização de jogos eletrônicos para fins educacionais têm crescido nos últimos anos e, a cada vez mais, vem ganhando adeptos e pesquisadores ${ }^{1}$ que defendem a aprendizagem baseada em jogos como forma de atender as demandas educacionais do aluno do século XXI. Mas agora que temos os holofotes voltados para os games, como eles têm sido utilizados em contextos de ensino-aprendizagem? [Eck 2006]. Uma discussão recorrente concentra-se na dificuldade de professores trazerem os games para seus contextos de ensino-aprendizagem, pois para muitos é um desafio encontrar e utilizar bons jogos educacionais. Muitos desses games carecem de princípios pedagógicos ou não são adaptáveis às demandas educacionais do professor, o que dificulta aplica-los em sala de aula [Balasubramanian e Wilson 2006].

\footnotetext{
${ }^{1}$ Ver Prensky (2012) e Squire (2007).
} 
Segundo Klopfer et. al. (2009) esse problema também é decorrente do planejamento errôneo que muitos designers adotam ao projetar um game educacional. Para que um game atenda eficientemente as necessidades do professor, faz-se necessária a presença e interação de educadores capazes de trabalhar conjuntamente no planejamento do jogo, para que a inserção do aspecto educacional seja, desde o princípio, atrelado e balanceado aos demais elementos básicos da jogabilidade, como a estética, a mecânica, a narrativa e a tecnologia [Leite e Mendonça 2013].

Assim, é nesse contexto que o Laboratório de Objetos de Aprendizagem (LOA) ${ }^{2}$ da UFSCar vem desenvolvendo suas pesquisas concentradas na utilização dos games como objetos capazes de proporcionar um aprendizado lúdico ao estudante/jogador e para atender as demandas de professores. A equipe vem trabalhando no desenvolvimento do jogo Musikinésia, game educacional gratuito para computadores e tablets idealizado para ensinar e aprimorar o conhecimento dos jogadores acerca de teclado musical, além de trabalhar outros conceitos musicais básicos, como leitura de pentagrama na clave de sol, acidentes (sustenidos e bemóis) e variação de andamentos. Assim, no item a seguir será descrita a metodologia adotada tanto para o desenvolvimento de um game educacional aos alunos/jogadores quanto para atender as demandas educacionais dos professores de teclado.

\section{Metodologia}

O projeto surgiu a partir de uma demanda apresentada por um professor do curso de Licenciatura em Música da UFSCar: criar um objeto de aprendizagem capaz de auxiliar os alunos de cursos presenciais e a distância na identificação das notas no teclado musical. Assim, para atender à proposta, a equipe desenvolvedora seguiu os seguintes procedimentos metodológicos:

1. Estudos e pesquisas nas áreas de design de interação [Rogers et. al. 2013] e avaliação de jogos educacionais, realizados por meio de encontros semanais com a participação dos estudantes e docentes do projeto;

2. Pesquisa sobre o conteúdo específico e trabalhos relacionados;

3. Levantamento de demandas de outros professores do Ensino Técnico e de graduação em Música, relacionadas à demanda apresentada inicialmente;

4. Concepção do jogo com base em demandas identificadas (brainstorm; definição inicial de mecânica, narrativa, arte, tecnologia);

5. Criação de um protótipo de alta fidelidade e realização de sessões de testes com diferentes perfis de usuário (no escopo do público-alvo);

6. Ciclos iterativos de testes, análises, refinamentos do design/protótipo.

7. Utilização de métodos tradicionais de avaliação, como observação de uso.

O desenvolvimento do projeto tem sido realizado por quatro estudantes de graduação (cursos de Música, Computação, Audiovisual) e um aluno de mestrado em Educação, sob a orientação de docentes das áreas de Música, Computação e Educação.

\footnotetext{
2 Espaço interdisciplinar de estudos e pesquisas de novas tecnologias e metodologias para o desenvolvimento de objetos de aprendizagem interativos abertos, concentradas na utilização dos games. Website: http://www.loa.sead.ufscar.br
} 
Por se tratar de um grupo misto, o jogo tem sido desenvolvido de forma equilibrada e colaborativa: enquanto os programadores e os ilustradores se empenhavam na elaboração de uma mecânica divertida e funcional ao jogador, os educadores e projetistas construíam um sistema de aprendizagem significativo e didático, de forma que não fosse ofuscada pela narrativa e por outros elementos. $\mathrm{O}$ projeto ainda tem contado com a constante colaboração de professores de Música do ensino técnico e superior na revisão dos conceitos educacionais presentes no projeto, os quais participaram por meio de um espaço virtual e questionários on-line.

\section{Trabalhos Relacionados}

A utilização de jogos em contextos de ensino-aprendizagem tem crescido nos últimos anos como uma forma eficaz de atender as demandas educacionais da atualidade. Prensky (2012) observa a necessidade de se rever as teorias e práticas educacionais para que estejam mais adequadas aos novos estilos de aprendizagem, e defende que essas práticas sejam baseadas em jogos digitais, justamente por estarem alinhadas com as necessidades e os estilos de aprendizagem da geração atual e futura de alunos, por motivar e por ser versátil, podendo ser adaptada a diferentes disciplinas, informações ou habilidades a serem aprendidas. Squire (2007) destaca que a aprendizagem baseada em jogos pode engajar os alunos em atividades significativas e permitir que assumam novas identidades, explorem mundos e aprendam. Gee (2005) defende que as escolas deveriam pautar seus planejamentos de ensino seguindo a mesma lógica dos games, ou seja, em focar mais na solução de problemas do que meramente na aquisição de informações, oferecendo um aprendizado mais significativo e, por que não, divertido.

Quanto à utilização de jogos voltada ao ensino de música, Motta e Garone (2013) trazem um exemplo de design instrucional de um jogo com enfoque em ditados melódicos. Os autores fazem uma abordagem das tecnologias como recursos capazes de complementar o processo de ensino de música, além de discutirem como os games podem atuar como facilitadores no processo de aprendizagem de conhecimentos musicais específicos. Nesse sentido, os games contribuem com o processo de aprendizagem por serem tecnologias digitais dotadas de propriedades sonoro-visuais interativos, que acabam funcionando como estímulos à assimilação de conteúdos musicais. No caso de Musikinésia, por exemplo, essa relação ocorre principalmente no sentido de relacionar as teclas do teclado musical às posições de suas respectivas notas no pentagrama (estímulos visuais). Além disso, os sons funcionam como estímulos capazes de colaborar na memorização das teclas, que podem ser associadas conforme o jogador interage com o teclado e atenta-se à gradação e diferença de alturas entre as teclas (como numa escala natural ascendente de Dó a Si, por exemplo).

Ainda sobre a importância dos estímulos sonoros, Jesus, Uriarte e Raabe (2008) trazem o exemplo de Zorelha, objeto de aprendizagem desenvolvido para auxiliar crianças na construção do conhecimento musical por meio da exploração sonora. Os autores destacam a importância de oferecer uma reprodução sonora de qualidade dos instrumentos virtuais no software, pois isso permitirá que os alunos tenham uma experiência mais fiel a real sonoridade dos instrumentos. Similarmente, a produção das músicas e notas do teclado de Musikinésia ocorreu pelo software de produção musical Reason, o qual possui um banco de samplers de gravações de instrumentos musicais e que podem ser reproduzidos digitalmente, assemelhando-se a real performance de instrumentos. 


\section{Apresentação do Protótipo}

Após o planejamento e estudo detalhado de como os elementos básicos constituiriam a jogabilidade, foi dado início à fase de implementação do jogo. $\mathrm{O}$ desenvolvimento e codificação do game, bem como as produções das músicas, elementos visuais e planejamento das fases aliadas aos objetivos educacionais ocorreram de forma conjunta, cujo processo resultou na criação de um protótipo de alta fidelidade ${ }^{3}$ [Bordini et. al. 2014a].

O jogo traz a bem humorada narrativa de Tom, um jovem filho de músico que encontra um teclado musical dotado de um poder especial chamado musikinésis (Fig. 1). No entanto, leigo em música, o protagonista decide aprender o instrumento para descobrir seus dotes mágicos e, para isso, embarca numa aventura por três mundos diferentes (Subúrbio, Máfia e Pirata) para adquirir novos conhecimentos musicais.

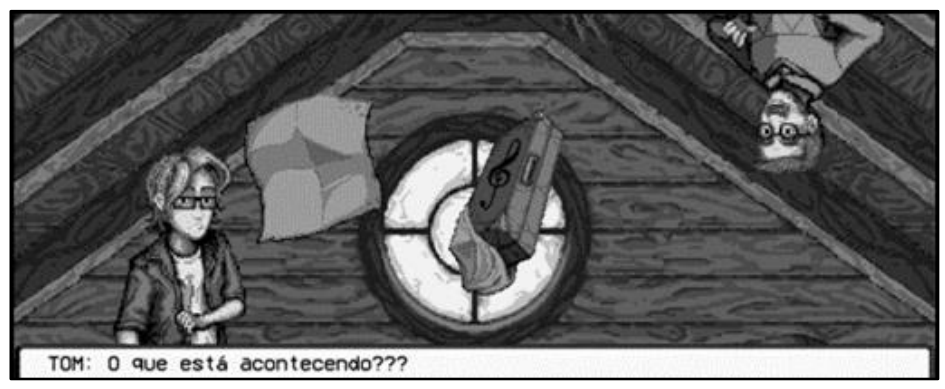

Figura 1. Cena de Diálogo entre Tom e seu pai

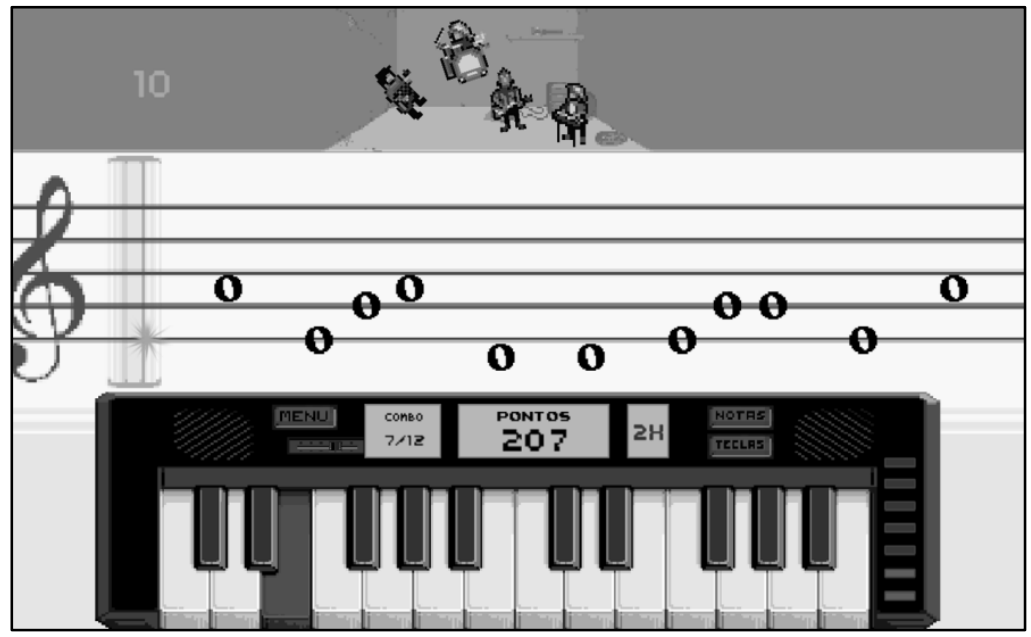

Figura 2. Tela do jogo Musikinésia

A mecânica baseia-se no ato de tocar as notas de uma linha melódica utilizando o teclado musical, pressionando as teclas correspondentes com o mouse ou com o teclado QWERTY (teclado normal dos computadores) (Fig. 2). Essas notas atravessam a tela da direita para a esquerda e o jogador deve tocá-las no momento em que entrarem numa região delimitada na partitura, onde é preciso pressionar as teclas correspondentes

\footnotetext{
${ }^{3}$ Segundo Rogers et. al. (2013), protótipo de alta fidelidade é aquele que utiliza materiais que se espera que estejam no produto final e, portanto, se assemelha em muito ao resultado final pretendido, diferente do protótipo de baixa fidelidade, o qual não se parece com o produto final e é constituído de materiais diferentes da versão final pretendida (como papel ao invés de telas eletrônicas, por exemplo).
} 
às respectivas notas. Caso o jogador cometa uma quantidade grande de erros, seu medidor de desempenho diminuirá e ele precisará recomeçar a música.

As fases foram projetadas para terem dificuldade gradativa, com a execução de músicas mais simples no início até as de nível mais elevado ao final. Existem dois modos jogáveis: Modo Campanha, o qual se trata do modo principal em que o jogador progride por onze fases de nível gradativo de dificuldade, acompanhado de tutoriais explicando os conceitos básicos de identificação das notas no teclado e outros elementos musicais; e o Modo Treino, no qual o jogador poderá praticar as músicas para se aperfeiçoar. Além disso, o jogo possui um Sistema de Pontuação que funciona como um importante elemento do jogo que indica a qualidade do desempenho do jogador. Esse sistema encontra-se no corpo do teclado (Fig. 3) e é composto por: Medidor de Desempenho, o qual delimita a quantidade de erros que o jogador pode cometer na música; Pontos, que demonstra o quanto o jogador contabiliza a cada acerto; Combo, o qual registra o número de acertos realizados sequencialmente; e, por fim, o Multiplicador de Pontos, que funciona como um multiplicador dos pontos que o jogador realiza seguidamente.

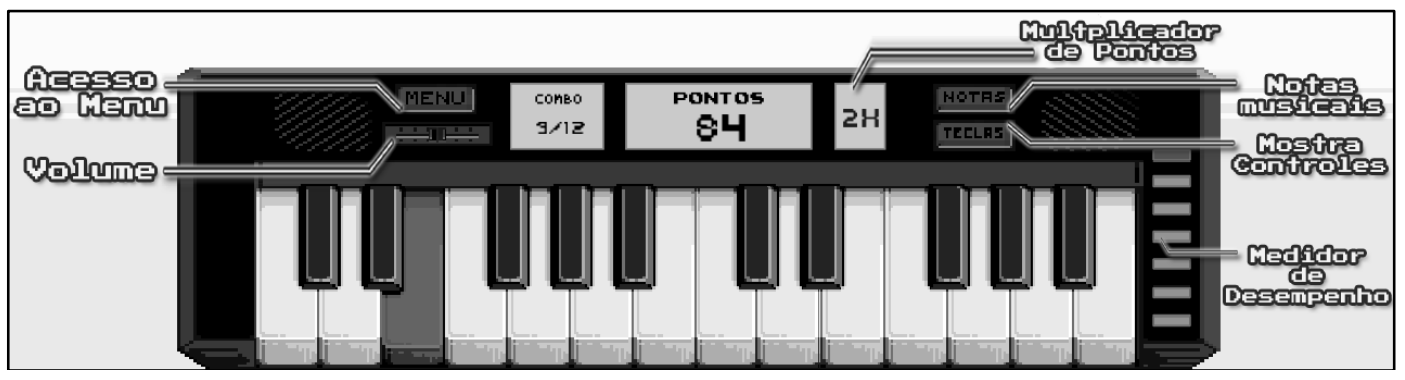

Figura 3. Funcionalidades da Interface e Sistema de Pontuação

Como visto nas Figuras 1, 2 e 3, o jogo possui um visual 2D, com gráficos desenhados seguindo o estilo Pixel Art (arte pixelizada). Esse estilo de visual foi escolhido por ser de leve processamento e consonante ao tom cômico da narrativa do game.

Todas as músicas do jogo receberam especial atenção durante seu processo de design. Dois estudantes e um professor de Música elaboraram um esquema de aprendizagem com base na compreensão de como o jogador/estudante aprende a ler uma partitura junto com o teclado. Assim, as músicas foram produzidas seguindo um plano de composição no qual constava a indicação das notas que deveriam ser utilizados para cada fase e o estilo musical consonante a cada mundo da aventura.

Paralelamente à aprendizagem de teclas do teclado musical, o jogo visa favorecer a aprendizagem de outras habilidades musicais. $\mathrm{Na}$ tabela abaixo é exemplificado como esses conceitos musicais são trabalhados paralelamente à narrativa, dividido pelas fases do game:

Tabela 1. Matriz de Aprendizagem separada por conjunto de fases

\begin{tabular}{|c|c|c|}
\hline FASE & CONCEITO/HABILIDADE & NARRATIVA \\
\hline \multirow{3}{*}{ Subúrbio } & $\begin{array}{c}\text { Introdução às noções básicas de } \\
\text { leitura musical (pentagrama e clave } \\
\text { de sol) e identificação das notas no }\end{array}$ & $\begin{array}{c}\text { O pai de Tom ensina os conceitos } \\
\text { básicos do instrumento e de teoria na } \\
1^{\mathrm{a}} \text { fase (tutorial) }\end{array}$ \\
\hline
\end{tabular}




\begin{tabular}{|c|c|c|}
\hline Máfia & $\begin{array}{c}\text { teclado musical } \\
\text { Andamento (velocidade da música). } \\
\text { Ex: allegro, moderato, presto }\end{array}$ & $\begin{array}{c}\text { O chefe Dom Macarrone desafia Tom } \\
\text { a tocar músicas com alteração da } \\
\text { velocidade }\end{array}$ \\
\hline Pirata & Acréscimo de Sustenidos e Bemóis & $\begin{array}{c}\text { Tom precisa ajudar o Pirata Morgan a } \\
\text { capturar outro pirata e aprende a } \\
\text { causar "acidentes" usando a } \\
\text { musikinésis }\end{array}$ \\
\hline
\end{tabular}

Além disso, o jogo possui quebra-cabeças musicais (puzzles) durante o Modo Campanha que se baseiam em três situações diferentes de resolução de problemas. Por exemplo, o primeiro deles baseia-se em um desafio em que Tom precisa pressionar teclas específicas no teclado (Dó - Fá e Mi - Si) para mover uma pintura torta na parede e levá-la até um local demarcado (Fig. 4). Este quebra-cabeça foi projetado para facilitar o entendimento do jogador acerca da localização de teclas no teclado, por meio da identificação de teclas com formatos semelhantes.

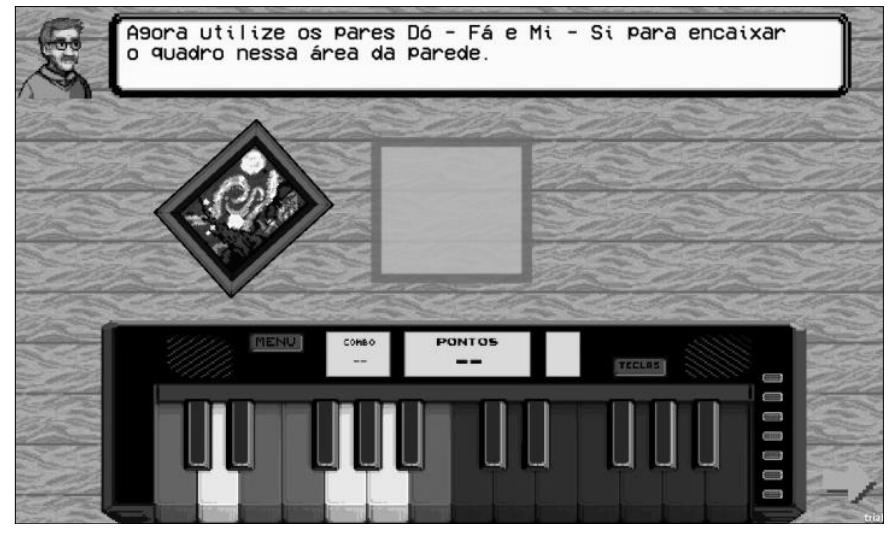

Figura 4. Exemplo de Quebra-Cabeça

\section{O Uso do jogo pelo Professor}

Ademais, o jogo Musikinésia foi projetado para que professores de Música o adaptem conforme suas demandas educacionais. Diante disso, foi pensado no oferecimento de alguns elementos importantes para auxiliá-los em sua utilização em sala de aula.

\subsection{Inserção de novas músicas por meio de arquivos MIDI}

Por meio do motor de jogo Unity 5 (linguagem C\#), a equipe desenvolvedora vem trabalhando em uma aplicação que permitirá a criação de melodias por meio da importação de arquivos $\mathrm{MIDI}^{4}$ no sistema do jogo, o qual automaticamente irá gerar as notas escritas para serem tocadas por meio de sua mecânica. Essa função dará autonomia para que o professor crie seus próprios conteúdos musicais e os compartilhe com os alunos, ampliando as possibilidades de trabalhar melodias e outros conceitos musicais de forma colaborativa [Ficheman et. al. 2003].

\footnotetext{
${ }^{4}$ Inventado em 1983, MIDI (Musical Instrument Digital Interface) é um protocolo de comunicação que permite instrumentos digitais interagirem entre si e com computadores. Um arquivo MIDI não contém sons, apenas instruções descrevendo as notas tocadas em uma performance e as informações sobre elas [Hansen s/a].
} 


\subsection{Jogando com teclado MIDI/USB}

Musikinésia permite a integração de um teclado MIDI/USB que pode ser usado como controle para a execução das músicas. Esta opção pode ser um recurso útil aos professores que queiram usar o jogo para aprimorar o processo de aprendizagem de teclado musical do aluno, pois, além de ser um fator motivacional devido ao aspecto lúdico do game, a utilização de um teclado MIDI/USB permite que o aluno tenha uma experiência natural ao jogar, aproximando-o da real prática de tocar um teclado.

\subsection{Recurso Educacional Aberto}

O acesso aberto a todos os componentes de Musikinésia ${ }^{5}$ para adaptação e, mesmo para o desenvolvimento de outro jogo educacional, é um importante fator para atendimento das demandas educacionais dos professores. Por mais que o jogo em si traga diferentes possibilidades de adaptação para o ensino (aprendizagem das teclas, leitura musical, andamentos, postura, etc.), Musikinésia prioriza o ensino de teclado e não contempla outras habilidades e conhecimentos do campo da Música (como durações, leitura em diferentes claves, intervalos, campo harmônico, etc).

\section{Avaliação}

Anteriormente à aplicação descrita nesse trabalho, foi realizado um processo de testes com oito pessoas voluntárias e quatro professores de Música, os quais testaram o game utilizando o mouse e o teclado QWERTY. Com os resultados obtidos nesse primeiro processo, cujos dados foram coletados por meio de questionários online e entrevistas, foi possível realizar ajustes referentes à interface (disposição das informações na tela) e mecânica do jogo. Esse processo é detalhado Bordini et. al. (2014b).

No segundo processo de testes descrito a seguir, o protótipo foi validado por meio de uma aplicação presencial com alunos e professores de um curso de Licenciatura em Música, com utilização de um teclado MIDI/USB. Nesse processo foi observado tanto o desempenho dos alunos quanto a utilização do jogo pelos professores de teclado.

\subsection{Processo de testes com os alunos}

Nessa etapa foram realizados testes funcionais com o público-alvo, que segundo Fernandes e Dias (2006), devem garantir que o jogo contenha todos os requisitos, contidos no Game Design, implementados corretamente. A função de gerente de teste foi assumida por um dos designers do jogo, o qual, além de preparar os instrumentos para coleta de dados com base em referências de playtesting [Fullerton 2008] e avaliação de jogos educacionais [Fu et. al. 2009], também foi responsável pela observação dos testes durante o processo. A função do observador, nesse caso, referiuse à observação de como o jogador se relaciona com o objeto testado, percebendo se o jogo consegue imergi-lo em uma experiência lúdica e verificar se as instruções para manuseamento dos controles são claras e objetivas.

\footnotetext{
${ }^{5} \mathrm{O}$ jogo, bem como todos os seus componentes, ficarão disponíveis para a comunidade no Repositório Digital Livre Saber (livresaber.sead.ufscar.br), repositório digital de acesso livre da SEaD/UFSCar, onde está sendo organizado um acervo de objetos educacionais multimídia produzidos como recursos educacionais abertos.
} 
Assim, os testes ocorreram com dois grupos de alunos da graduação de Licenciatura em Música da UFSCar durante as aulas da disciplina de Teclado I, ministrada por dois professores. Cada turma possuía sete alunos, sendo em sua maioria conhecedores de música com habilidade de leitura de partitura, porém com pouco ou nenhum conhecimento em teclado. Para cada aplicação foram montados três sets com o jogo em uma sala reservada, compostos por um notebook, um teclado com cabo MIDI/USB e fones de ouvido; e cada sessão de testes teve duração média de 40 minutos, sendo 20 para o teste com o jogo e 20 para discussão em grupo. Primeiramente foi realizada uma breve apresentação do jogo, sem aprofundamento de detalhes, pois se pretendia analisar o quanto o game seria capaz de apresentar seus objetivos e conteúdos de forma autocontida [Silveira e Carneiro 2012]. Em um segundo momento foi solicitado que os testadores jogassem o game enquanto o designer realizava uma observação sem intervenção direta com o testador. Ao final de cada teste, o designer realizou discussões acerca das impressões do jogo, fazendo questões referentes à jogabilidade básica, clareza dos objetivos educacionais e o quanto foi capaz de ensinar/aprimorar seu conhecimento musical. Os dados coletados foram registrados por meio de anotações e posteriormente repassados à equipe para análise coletiva.

\subsection{Utilização do jogo pelos professores}

Paralelamente ao processo de testes realizado com os alunos, foi possível acompanhar quais foram as estratégias pedagógicas dos professores para aplicação do game.

Apesar de o jogo possuir um conteúdo pré-estabelecido, os professores participantes o utilizaram para outro propósito, como melhorar o desempenho dos estudantes no que diz respeito à leitura à primeira vista, velocidade de associação entre as teclas do teclado com as notas contidas em uma pauta musical, postura do corpo e posicionamento das mãos sobre as teclas. Assim, nas aulas que antecederam a aplicação do jogo, ambos os professores utilizaram melodias de canções folclóricas brasileiras com o propósito de atentar os alunos para questões de postura das mãos sobre o instrumento, associação das teclas com as notas na partitura e execução das melodias sem visualização do teclado, cuja ideia principal foi melhorar a vinculação entre leitura da grafia (representação gráfica das notas) e a execução das notas indicadas a partir da sensação tátil de textura das teclas. O treinamento destas habilidades, além de estabelecer um vínculo com o conteúdo pedagógico de Musikinésia, prepararam os alunos para a aplicação do jogo, o que tornou sua aplicação contextualizada.

\subsection{Análise dos Resultados}

Os feedbacks obtidos tanto por meio dos testes com os alunos, quanto pela observação dos professores, de forma geral, apontaram que Musikinésia conseguiu atender os objetivos de ensino das teclas de teclado e de outros conceitos musicais. Por outro lado, foi possível observar que alguns alunos se sentiram confusos em relação ao posicionamento correto das mãos sobre o teclado e tiveram dificuldades em vencer algumas fases. Esses feedbacks indicaram a necessidade de balanceamento da dificuldade do jogo e inserção de informações sobre a posição correta das mãos no teclado em músicas específicas do game. Em relação ao desempenho dos professores na aplicação do game às classes, foi possível analisar que em um primeiro momento ambos tiveram certa dificuldade de realizar a aplicação prática do jogo em suas aulas, justamente por se tratar de uma atividade até então inédita para eles. Segundo seus 
relatos, os maiores receios em trazer um jogo para a sala de aula foram de ele ser mal utilizado pelos alunos ou aplicado de forma aleatória, sem que eles enxergassem uma conexão entre o game e o conteúdo da disciplina de teclado. Outra insegurança dos professores foi a de uma possível perda de tempo para a preparação do ambiente com o game, o que poderia prejudicar no andamento da aula e, consequentemente, no atraso dos conteúdos da disciplina. Assim, segundo Grando (2001), caso o professor não tenha preparo suficiente para lidar com tais tecnologias e previamente entender suas funcionalidades, o jogo poderá se tornar uma desvantagem para seu uso em sala de aula.

Por outro lado, devido à flexibilidade de conteúdos e de formas de jogabilidade do game, ambos os professores conseguiram inseri-lo em suas aulas de forma contextualizada e eficaz ao aprendizado dos alunos, realizando uma apropriação antes de trazer o game à classe (familiarização com o seu conteúdo, jogabilidade e elaboração de estratégias capazes de aliar o jogo ao conteúdo da disciplina), orientação durante o processo de aplicação (condução dos alunos para interação com o game e observação do desempenho deles) e posterior debate com a classe referente às impressões com o Musikinésia e associação dos conteúdos vistos na disciplina com os que estavam presentes no jogo. Este procedimento realizado pelos professores revelou-se como uma forma eficaz de utilização do jogo em sala de aula.

\section{Conclusão}

Com base nos resultados obtidos no processo de testes, pôde-se concluir que Musikinésia revela-se como uma eficaz contribuição para as áreas de Música e Informática, tanto para professores que desejam utilizar tal recurso para o ensino de teclado e leitura de partitura quanto para alunos que almejam aprender o instrumento de forma lúdica e significativa. $O$ jogo ainda precisará passar por refinamentos, como oferecer suporte ao jogador para posicionamento correto das mãos sobre o teclado e finalizar o aplicativo que possibilitará a inserção de arquivos MIDI no sistema do jogo, o qual ampliará a gama de possibilidades de sua utilização por professores em diferentes contextos de ensino-aprendizagem de Música.

\section{Agradecimentos}

Os autores agradecem o apoio concedido pelo Edital PROEXT 2014 - MEC/SESu; à Secretaria de Educação à Distância $(\mathrm{SEaD})$, à Pró-Reitoria de Extensão da UFSCar e à todos os professores, alunos e amigos que, direta ou indiretamente, contribuíram com a realização deste projeto.

\section{Referências}

Balasubramanian, N. e Wilson, B. G. (2006). Games and simulations. In Society for Information Technology and Teacher Education. International Conference.

Bordini, R. A., Otsuka, J. L., Beder, D. M., Fonseca, L. L., Freitas, P. G., Nunes, A. P., Santiago, D. L. Santiago, G. L. e Oliveira, M. R. (2014a). Processo de Design de um Jogo Eletrônico Para o Aprendizado de Teclado Musical. In XIII Simpósio Brasileiro de Jogos e Entretenimento Digital. SBGames 2014. Porto Alegre/RS.

(2014b). Avaliação do Protótipo de um Game Educacional de Música. In XIX

Conferência Internacional sobre Informática na Educação. TISE 2014. Fortaleza/CE. 
Eck, R. (2006) "Digital game-based learning: it's not just the digital natives who are restless". Educause.

Fernandes, T. e Dias, A. (2006) Processo de Testes para Desenvolvimento de Jogos Celulares. In Procedings of the V Brazilan Symposium on Computer Games and Digital Enterainment (SBGames Computing). ShortPaper.

Ficheman, I. K., Lipas, R. A., Krüger, S. A. e Lopes, R. (2003) Editor Musical: uma Aplicação para a Aprendizagem de Música apoiada por Meios Eletrônicos Interativos. In XIV Simpósio Brasileiro de Informática na Educação. IM/UFRJ.

Fu, F. L., Su, R. C., e Yu, S. C. (2009) EGameFlow: A Scale to Measure Learners' Enjoyment of E-Learning Games. In Computers \& Education. Elsevier Educational Research Programme.

Fullerton, T. (2008) "Game Design Workshop: A Playcentric Approach to Creating Innovative Games”. Morgan Kaufmann, p. 470.

Gee, J. P. (2005) “Good video games and good learning”. Phi Kappa Phi Forum, no 2.

Grando, R. C (2001). "O jogo na educação: aspectos didático-metodológicos do jogo na educação matemática". Unicamp.

Hansen, B. (s/a) "Musical Instrument Digital Interface". Disponível em $<$ http://www.hansenb.pdx.edu/pdf/MIDI.pdf $>$ acesso em 26/05/2015.

Jesus, E.A., Uriarte, M.Z. e Raabe, A.L.A. (2008) Zorelha: um objeto de aprendizagem para auxiliar o desenvolvimento musical infantil. In XIX Simpósio Brasileiro de Informática na Educação (SBIE 2008).

Klopfer, E., Osterweil, S., e Salen, K. (2009). Moving Learning Games Forward: Obstacles, Opportunities e Openness. In The Education Arcade. Massachusetts Institute of Technology.

Leite, P. S. e Mendonça, V. G. (2013) Diretrizes para game design de jogos educacionais. Pontifícia Universidade Católica do Paraná (PUC-PR). In Proceedings of SBGames. Art \& Design Track - Full Papers.

Motta, F. C. e Garone, P. M. C. (2013) Melodic: design instrucional de um jogo para o ensino de música. Universidade Federal do Espírito Santo. In Proceedings of SBGames. Art \& Design Track - Full Papers.

Prensky, M. (2012) “Aprendizagem baseada em jogos digitais”. São Paulo: Editora Senac São Paulo.

Rogers, Y., Sharp, H. e Preece, J. (2013). "Design de Interação: Além da Interação Humano-Computador. 3. Ed. Porto Alegre, Brasil: Bookman.

Silveira, M. S. e Carneiro, M. L. (2012) Diretrizes para a Avaliação da Usabilidade de Objetos de Aprendizagem. In Anais do $23^{\circ}$ Simpósio Brasileiro de Informática na Educação (SBIE 2012). Rio de Janeiro, p. 26-30.

Squire, K. D. (2007) “Games, Learning and Society: Building a Field”. Educational Technology. 